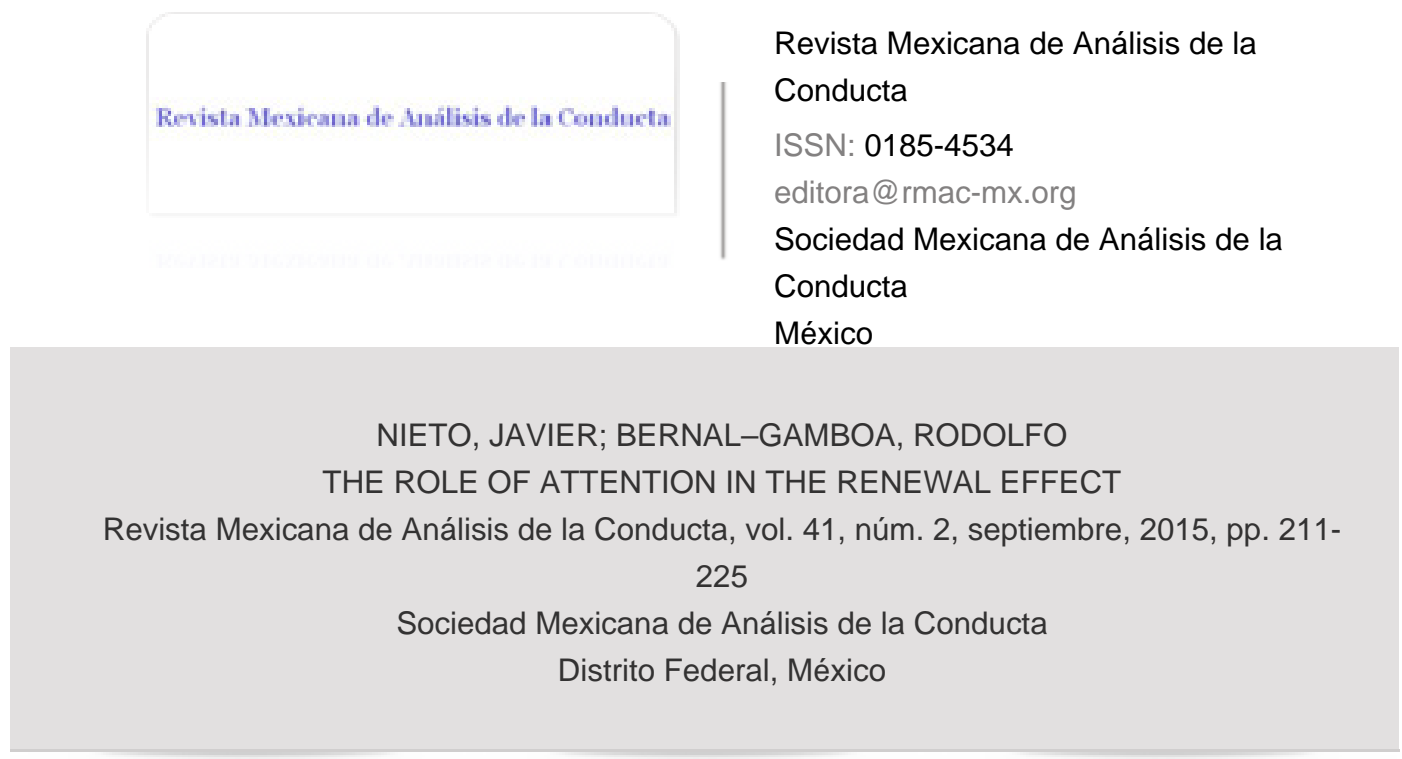

Available in: http://www.redalyc.org/articulo.oa?id=59341195012

- How to cite

- Complete issue

More information about this article

Journal's homepage in redalyc.org

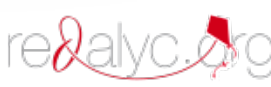

Scientific Information System Network of Scientific Journals from Latin America, the Caribbean, Spain and Portugal Non-profit academic project, developed under the open access initiative 


\title{
THE ROLE OF ATTENTION IN THE RENEWAL EFFECT
}

\author{
EL PAPEL DE LA ATENCIÓN EN EL EFECTO DE LA RENOVACIÓN \\ JAVIER NIETO AND RODOLFO BERNAL-GAMBOA \\ NATIONAL AUTONOMOUS UNIVERSITY OF MEXICO
}

\begin{abstract}
The renewal effect is a key phenomenon in understanding the underlying mechanism of recovery from extinction. Findings in renewal strongly suggest that contextual cues play an important role in retrieving previously extinguished responses. The retrievalof-information theory (Bouton, 1993) has been the main theoretical view in this area for the last 20 years. However, some inconsistent data suggest that Bouton's explanation is incomplete. This article reviews recent research indicating that attention could be another mechanism that underlies renewal and other recovery effects. Implications for learning theory and interventions in applied settings are discussed.

Keywords: attention, extinction, context processing, rats, renewal
\end{abstract}

\section{Resumen}

El efecto de renovación es un fenómeno clave para el entendimiento del mecanismo subyacente de la recuperación de la extinción. Los hallazgos de renovación sugieren que las claves contextuales tienen un papel importante en la recuperación de respuestas previamente extinguidas. La teoría de la recuperación de la información (Bouton, 1993) ha sido el principal punto de vista teórico en esta área durante los

Correspondence concerning to this article may be addressed to Javier Nieto (janigu@unam.mx). Facultad de Psicología, División de Investigación y Estudios de Posgrado, Universidad Nacional Autónoma de México, Cubículo 16, Edificio D, 1er Piso; Ciudad Universitaria, Coyoacán, Ciudad de México, CP 04510.

Preparation of the manuscript was supported by UNAM-DGAPA through grant project PAPIIT IN307113. We thank Jannet Herrera-Chávez for revising the language. 
últimos 20 años. No obstante, algunos datos inconsistentes sugieren que la explicación de Bouton es incompleta. En este artículo se revisa investigación reciente que indica que la atención puede ser otro mecanismo que subyace la renovación y otros efectos de recuperación. Se discuten las implicaciones para la teoría del aprendizaje y las intervenciones en ambientes aplicados.

Palabras clave: atención, extinción, procesamiento del contexto, ratas, renovación

Reduction in a previously trained response due to the omission of the unconditioned stimuli or reinforcement is known as extinction. Nowadays, it is widely accepted that extinction is not the same as unlearning (Delamater, 2004; Rescorla, 2001). That argument is based on the evidence from five response recovery phenomena (Bouton, 2014). In the renewal effect, an extinguished response returns whenever the subject is tested outside the extinction context (Bouton \& Bolles, 1979; Thomas, Larsen, \& Ayres, 2003). In spontaneous recovery, the retrieval of the extinguished behavior occurs merely by the passing of time (Pavlov, 1927; Rescorla, 2004). Reinstatement is an effect that shows that an extinguished responding may return by delivering the outcome independently of responding (Delamater, 1997; Sánchez-Carrasco, González-Martín, \& Nieto, 2011). In rapid reacquisition, a previously extinguished response can be retrieved due to the re-experience of the response-outcome contingencies (Capaldi, 1994; Woods \& Bouton, 2007). Finally, in resurgence, the recovery of one extinguished response occurs when a second response has undergone extinction (Epstein, 1983; Sánchez-Carrasco \& Nieto, 2005).

Those effects have been explained by different mechanisms. However, in recent years some authors have claimed that although all of them involve distinct procedures they all might share a common mechanism (Bouton, Winterbauer, \& Todd, 2012; see also McConnell \& Miller, 2014; but cf. Podlesnik \& Kelly, 2015, this issue). The present article focuses on renewal to explore the common mechanism shared by all of the aforementioned response recovery phenomena. Specifically, we analyze herein evidence that supports a recent model that explains renewal: attentional theory of context processing (ATCP). Additionally, given that renewal has been proposed as a model for understanding the mechanism of lapse and relapse, we will note that ATCP has exclusively and relevant implications that could be used to thwart relapse. Thus, in the first part of the present review the renewal effect is illustrated, and the retrieval of information theory (RIT) is reviewed in some detail (see Bouton, 1994). Then, we briefly present some research conducted to explain why the retrieval of extinction learning is highly context specific. Following this, studies testing predictions of the attentional theory of context processing (ATCP) are reviewed. Finally, we note some clinical implications. 


\section{The renewal effect: A key phenomenon}

The partial recovery of an extinguished response by changing the context between extinction and test has been studied using three different designs: $A B A, A A B$ and $A B C$ renewal. For example, Bernal-Gamboa, Carrasco-López and Nieto (2014) trained three groups of rats in a free-operant procedure. During acquisition, all rats pressed the lever for food during six days in Context $\mathrm{A}$. Then, all rats received an extinction treatment for the next four days. In the $A A B$ group, the rats' response was extinguished in the same context as was present in acquisition (A), while for Groups $A B A$ and $A B C$ extinction took place in a different context (B). Finally, renewal was tested in one of the three contexts (see Figure 1). Rats responded more in the test when they were returned to the original context than when they received testing in the extinction context (ABA renewal; cf. Bouton \& Bolles, 1979; Bouton \& Peck, 1989, Nakajima, Tanaka, Urushihara, \& Imada, 2000; Vila \& Rosas, 2001). A similar pattern obtained (i. e., responding more in the renewal context than in extinction context) when acquisition and extinction was conducted in Context $\mathrm{A}$ and testing occurred in Context $\mathrm{B}$ (AAB renewal; Bouton \& Ricker, 1994; Tamai \& Nakajima, 2000; Rosas \& Callejas-Aguilera, 2006), and when rats received all phases in three different contexts (ABC renewal; Bernal-Gamboa et al., 2012; Bouton, Todd, Vurbic, \& Winterbauer, 2011; Nelson, Sanjuan, Vadillo-Ruiz Pérez, \& León, 2011; Rescorla, 2008). These results show two important things about renewal: 1) extinction is not permanent and 2) all types of renewal have been found in both operant and Pavlovian preparations, although they may not produce an equal level of renewal.

Research on renewal is relevant for different psychological areas such as theories of associative learning (Bouton \& Woods, 2008), neurobiological studies of learning and memory (Delamater \& Westbrook, 2014), emotional intelligence (Nelson, 2013) and models of lapse and relapse (Bouton, Woods, Moody, Sunsay, \& García-Gutiérrez, 2006; Crombag \& Shaham, 2002). Given that Bouton provided an explanation for renewal (and other interference phenomena) that has guided research in this area for more than 20 years, we describe in some detail his theoretical perspective.

\section{Retrieval of Information Theory}

Following the assumptions of other associative models, Bouton $(1993,1994)$ suggested that the associative memory is formed by nodes and by the associations among them (Hall, 2002). The retrieval of information theory (RIT) model proposes that during conditioning an excitatory association between the conditioned stimulus (CS) and unconditioned stimulus (US) is established. Bouton assumes that at the end of extinc- 


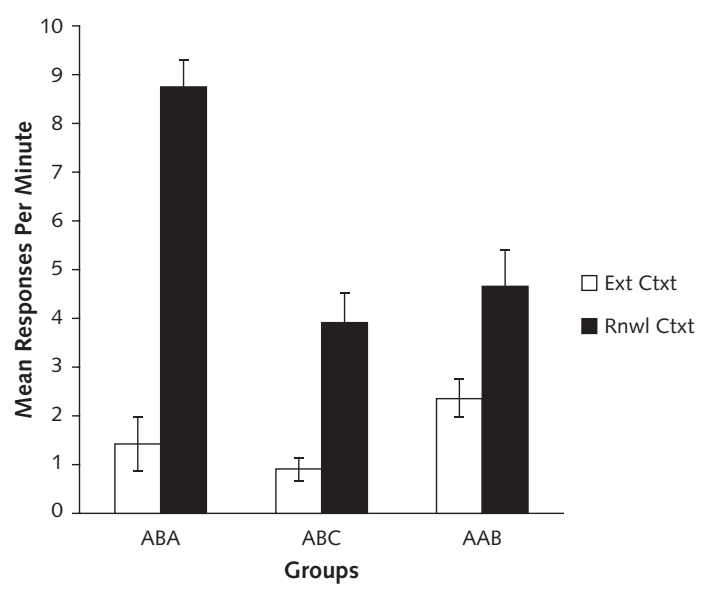

Figure 1. A within subject test for renewal of operant responses. Mean responding during test in both extinction contexts and renewal contexts. Error bars denote standard errors of the mean. Based on Bernal-Gamboa, Carrasco-López, and Nieto (2014).

tion the excitatory link between the CS and US is not lost but remains intact. However, a second, but inhibitory, association between the CS and the US is formed (see Konorski, 1948; Pearce \& Hall, 1980). Thus, the CS acquires both excitatory and inhibitory relations to the US.

According to Bouton (1994) activation of the inhibitory association depends on the contextual cues. Specifically, the background activates another node that acts as an AND logic gate. On the one hand, when the Context node and CS node are activating simultaneously, the inhibitory association suppresses activation of the US representation; therefore, subjects show extinction-like performance. On the other hand, no activation of the Context node would boost the excitatory association allowing the renewal of the conditioned response (CR). In conclusion, RIT assumes that it is necessary to be in the extinction context to remember the extinction learning. Moreover, according to this model renewal is a failure in the retrieval of extinction learning. Therefore, $\mathrm{ABA}, \mathrm{AAB}$ and $\mathrm{ABC}$ renewal are predicted.

\section{Why does the recovery of extinction learning depend on the context?}

To answer why the retrieval of extinction learning is context-dependent, Bouton proposed two hypotheses; both were built on features of the information in the situation. The first relies on the quality of information: given that during extinction inhibitory associations are acquired, then all inhibitory associations would show contextual dependency. However, pertinent research has indicated that both inhibitory and ex- 
citatory associations can generalize well across contexts (Bouton \& Nelson, 1994; Nelson \& Bouton, 1997). The other hypothesis relies on the sequence of information: given that extinction is the second learning about CS, then context dependence should be found only during second-learning. This was supported by animal data showing that regardless of the type of association (i.e., excitatory or inhibitory) only the second-learned information was sensitive to contextual changes (Nelson, 2002, 2009).

Although clear, the idea that only the second-learned information is modulated by contextual cues has been inconsistent with data obtained in both human and nonhuman animals. For example, Carranza-Jasso, Urcelay, Nieto, and Sánchez-Carrasco (2014) found that generalization of a first-learned appetitive CR (acquired in Context A) to a different context (B) was affected when an intertrial interval (ITI) with short durations was used rather than one with long durations (see also, Bonardi, Honey, \& Hall, 1990; Hall \& Honey, 1989). In experiments with human participants, the retrieval of simple excitatory conditioning has been shown to be context-specific. Using a computer game, Bernal-Gamboa, Alvarado, et al., (2012) trained two groups of participants to shoot an enemy vehicle in the presence of a visual stimulus $(X)$ in Context A. Participants in one group received three acquisition trials, while those in a second group received eight. During testing, all groups received presentations of $X$ in the same context where they were trained (A) and in a different context (B). Participants receiving three trials in Context $A$ did not transfer the correct response to Context B (see Figure 2; see also, León, Abad \& Rosas, 2010a), while those receiving eight trials did transfer the correct response to Context B.

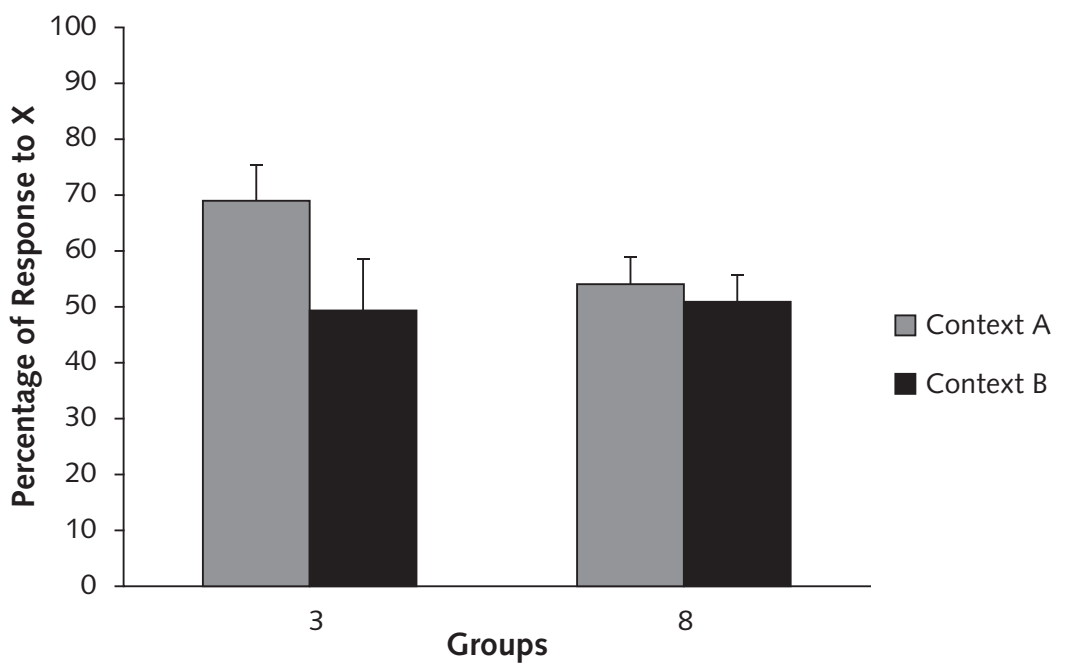

Figure 2. Mean of correct responding during test in presence of $\mathrm{X}$ for both groups 3 and 8 in contexts $\mathrm{A}$ and B. Error bars denote standard errors of the mean. Based on Bernal-Gamboa, Alvarado et al. (2012). 
The previous examples along with other results (see, León, Abad \& Rosas, 2010b; Lucke, Lachnit, Koenig, \& Uengoer, 2013; Lucke, Lachnit, Stüttgen, \& Uengoer, 2014; Preston, Dickinson, \& Mackintosh, 1986; Rosas, García-Gutiérrez \& Callejas-Aguilera, 2006) indicate that even the retrieval of the first-learned information is affected by context changes.

\section{Attentional Theory of Context Processing}

To account for such inconsistent findings, Rosas, Callejas-Aguilera, Ramos-Álvarez and Abad (2006) proposed the attentional theory of context processing (ATCP) as an extension of Bouton's theory. According to these authors, the context-dependence of information is based on a mechanism of attention to the contexts during learning. For example, if contexts are attended to, recovery of any information learned within the attended context becomes context-specific, regardless of whether it is the first or second information learned. Rosas et al., (2006) proposed that attention could be modulated by different factors (see also, Nieto \& Bernal-Gamboa, 2013). However, because of its relevance to the renewal effect we will focus on one factor: the ambiguity in the meaning of a cue produced by extinction.

Unlike Bouton, ATCP proposed that the contextual control in renewal relies on the modulation of attention and not on a feature of the information (second learned or ambiguous). This additional assumption allows it to predict that after extinction any information learned would become context-specific. Bernal-Gamboa and Nieto (2012) conducted an experiment using a conditioned taste aversion (CTA) procedure with rats to test that idea. Two groups of rats received free access to Flavor $X$ water, immediately after they received a lithium chloride ( $\mathrm{LiCl}$ ) injection in Context A. In the next phase, all rats drank Flavor $X$ during three trials without injection (extinction trials). Then, all groups received free access to Flavor $Y$ water, and this consumption was paired with an injection of $\mathrm{LiCl}$ in Context A. Finally, consumption of Flavor $\mathrm{Y}$ was measured in a test session in either Context A or Context B. During the test session, no injection occurred and water consumption was measured. According to Bouton, given the information that $Y$ is neither second-learned nor ambiguous information, both groups should show similar levels of consumption of $\mathrm{Y}$ in the test session. However, as the data in Figure 3 show, Bernal-Gamboa and Nieto's (2012) rats tested in Context $\mathrm{B}$ consumed more $\mathrm{Y}$-flavored water than did rats tested in Context $\mathrm{A}$, suggesting poor retrieval of the relation between $\mathrm{Y}$ and illness produced by the context change (see also, Rosas \& Callejas-Aguilera, 2007; but see Nelson, Lombas, \& León, 2011).

The findings previously mentioned are consistent with the ATCP because they suggest that after extinction of Flavor $\mathrm{X}$ rats attended to the context producing a contextual specificity in the learning of $\mathrm{Y}$. Similar results were obtained using temporal 


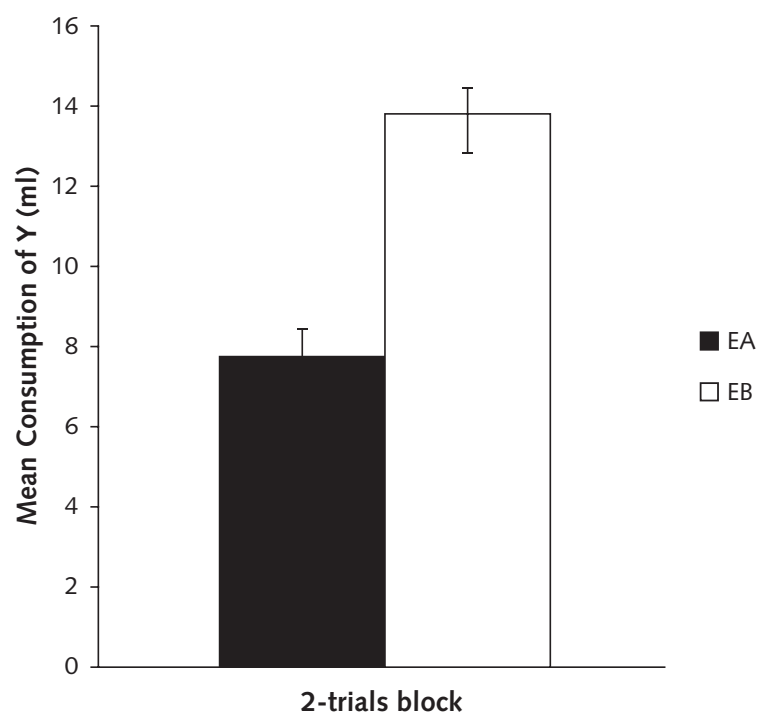

Figure 3. Mean consumption of $\mathrm{Y}$ during test for group EA and EB. Error bars denote standard errors of the mean. Based on Bernal-Gamboa and Nieto (2012).

contexts with rats (Bernal-Gamboa, Callejas-Aguilera, Nieto \& Rosas, 2013) and fictional contexts with human participants (Rosas \& Callejas-Aguilera, 2006; see also, Nelson \& Callejas-Aguilera, 2007; Nelson, Lamoureux, \& Leon, 2013).

Furthermore, there is evidence suggesting that once the attention to the context is aroused, this attentional modulation can be maintained even in different tasks. Recently, Bernal-Gamboa, Callejas-Aguilera, and Rosas (2014), trained two groups of rats to run down a straight alley (Context A) when water was at the end of the alley (Task 1). The next phase was conducted in Context A. Rats in Group NE received the identical treatment to that in the previous phase. Rats in Group E received only extinction trials. In the next phase, both groups were exposed to a second task, which consisted of a CTA trial in which Flavor $X$ was given in a different location (Context B). Finally, consumption of Flavor $X$ was measured in Context $C$. According to ATCP, experiencing extinction in Task 1 would make conditioning of Task 2 context-dependent. The data in Figure 4 show that the findings were consistent with that prediction: rats in Group E consumed more water flavored with $\mathrm{X}$ in Context $\mathrm{C}$ than did the Group NE rats (see also, Rosas \& Callejas-Aguilera, 2006). Furthermore, similar results obtained when the order of the tasks was reversed, acquisition and extinction of CTA (Task 1) was followed by running down the alley for water (Task 2; see Bernal-Gamboa et al., 2014). 


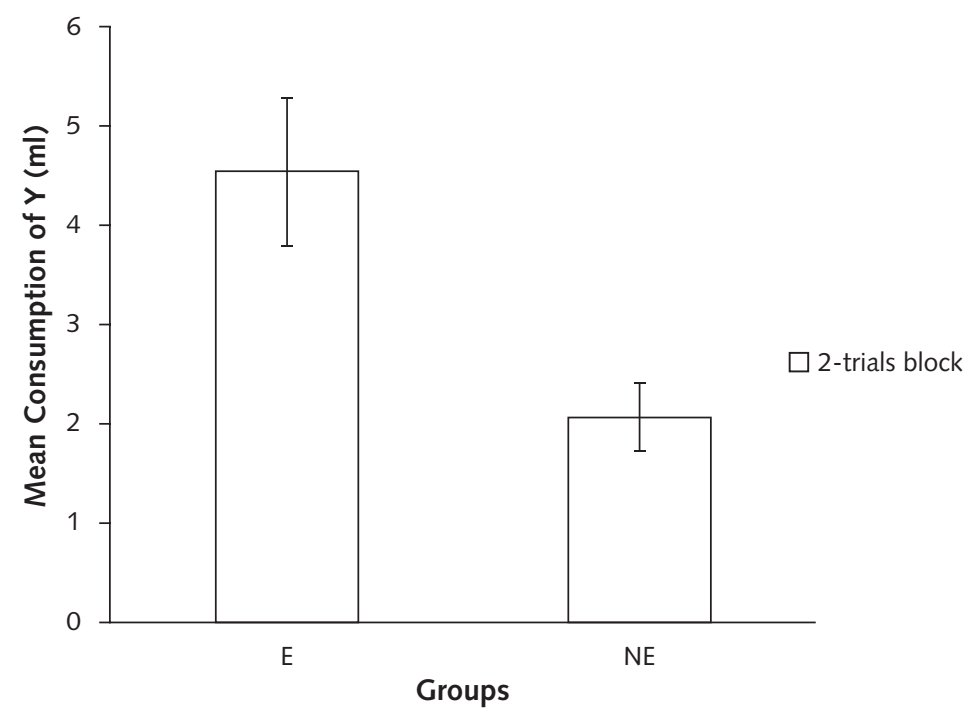

Figure 4. Mean consumption of $\mathrm{Y}$ during test for group $\mathrm{E}$ and $\mathrm{NE}$ in context $\mathrm{C}$. Error bars denote standard errors of the mean. Based on Bernal-Gamboa, Rosas, and Callejas-Aguilera (2014).

In conclusion, although ATCP is still in development, it seems a good candidate to explain a full range of findings for which the RIT cannot account. Moreover, its central construct has been supported with evidence. Recently, for example, Nelson et al., (2013) reported in a behavioral suppression task with humans, direct measures of attention to contextual cues during extinction. Assuming the participation of an attentional mechanism in renewal has implications for applied situations. In the next section, we address a key point derived from our suggestions about the mechanisms of renewal that could be used to prevent relapse.

\section{Clinical Implications}

Several learning theorists have proposed that the study of the renewal effect could contribute to a better understanding of some mechanisms of clinical relapse of unhealthy behavior (e.g., Bouton, 2011; Crombarg, Bossert, Koya, \& Shaham, 2008). Given that renewal (relapse) occurs outside the extinction context (therapist office), several authors have proposed it as an associative model of relapse after treatment (Bossert et al., 2004; Conklin \& Tiffany, 2002; Laborda, McConell, \& Miller, 2011). Thus, the development of long-term behavioral treatments to prevent renewal is of major interest to researchers in this area. 
A central assumption of the ATCP is that attention to contextual cues during learning is a critical factor that determines whether its retrieval would depend on the context or not. Thus, one implication is that if during treatment the therapist reduces the client's attention to the therapeutic setting, then the learning (therapeutic strategies) acquired there could be generalized to different environments, thwarting relapse.

Although that prediction has not been explored directly, recent findings could be promising. In a study using a human predictive learning task (Miller, Lefebvre, Lyon, Nelson, \& Molet, 2014), participants learned during Phase 1 that a medicine was associated with fever but not nausea. Then in Phase 2, a counterconditioning procedure was conducted in which the participants learned that the medicine produced nausea but not fever. Finally, participants were tested immediately or after a retention interval (temporal context). During the retention interval, one group received a focused - attention exercise, while the other one received a control exercise. Participants receiving the control exercise showed a spontaneous recovery of the initial learning acquired in Phase 1. However, spontaneous recovery was prevented when humans received the focus - attention exercise, because they recovered the information learned in Phase 2. Additionally, those participants showed similar predictive ratings than the participants that were tested immediately (for similar findings in resurgence see, McHugh, Procter, Herzog, Schock, \& Reed, 2012).

Despite the promising findings of Miller et al. (2014), it is important to note its preliminary nature. Thus, more research should be done using human and nonhuman animals, also different procedures (appetitive and aversive) need to be evaluated. In particular, we suggest that the development of nonverbal techniques that modulate attention to contextual cues could be relevant to studies with nonhuman animals.

Note that we are extending the efficacy of focus attention to prevent spontaneous recovery and resurgence to renewal, because there are authors that assume that such recovery effects share a common mechanism (Bouton et al., 2012). However, some researchers have claimed the contrary (see, Podlesnik \& Kelly, 2014, 2015 this issue; Shahan \& Sweeney, 2011). Thus, besides the benefits of evaluated treatments that thwarts relapse, this line of research could contribute as well to a theoretical level of analysis, by discovering whether recovery effects share or not a common mechanism.

\section{Summary}

The present article reviews some data consistent with the view that extinction is not the erasure of previously learned information. Specifically, the renewal effect indicates that contextual cues play a major role in the recovery of extinction learning. Although the RIT has guided the research in this area, inconsistent data has led Rosas et al. (2006) to propose the ATCP as an extension of RIT. The additional assumption of ATCP relies 
on an attentional mechanism to context rather than a specific feature of the information. Several studies have been conducted in order to test their predictions (see, Abad, Ramos-Álvarez, \& Rosas, 2009; Callejas-Aguilera \& Rosas, 2010; Nelson et al., 2013).

Because the overall results support the ATCP, it is important to continue testing its predictions and its generality in both human and nonhuman animals, and with different procedures. It also is important to evaluate whether the basic effect of contextual control arising as a function of extinction can be demonstrated in other recovery phenomena such as reinstatement or resurgence. Finally, given the therapeutic use of focus attention procedures in clinical settings (mindfulness), ATCP seems a good candidate to link basic and applied research in a successful way.

\section{References}

Abad, M. J. F., Ramos-Álvarez, M. M., \& Rosas, J. M. (2009). Partial reinforcement and context switch effects in human predictive learning. Quarterly Journal of Experimental Psychology. 62, 174-188.

Bernal-Gamboa, R., Callejas-Aguilera, J. E., Nieto, J., \& Rosas, J. M. (2013). Extinction makes conditioning time-dependent. Journal of Experimental Psychology: Animal Behavioral Processes, 39, 221-232.

Bernal-Gamboa, R., Rosas, J. M., \& Callejas-Aguilera, J. E. (2014). Experiencing extinction within a task makes nonextinguished information learned within a different task context-dependent. Psychonomic Bulletin \& Review, 21, 803-808.

Bernal-Gamboa, R., Alvarado, A., León, S. P., Nieto, J., Rosas, J. M., \& Vila, J. (2012). La Generalización entre contextos como función del entrenamiento en una tarea instrumental con humanos. Psychological Research Records, 2, 792-807.

Bernal-Gamboa, R., Carrasco-López, M., \& Nieto, J. (2014). Contrasting ABA, AAB and $A B C$ renewal in a free operant procedure. The Spanish Journal of Psychology. Bernal-Gamboa, R., Juárez, Y., González-Martín, G., Carranza, R., Sánchez-Carrasco, L., \& Nieto, J. (2012). ABA, $A A B$ and $A B C$ renewal in taste aversion learning. Psicológica, 33, 1-13.

Bernal-Gamboa, R., \& Nieto, J. (2012). Context-switch effect produced by the ambiguity of the meaning of a cue. Psychological Research Records, 2, 899-909.

Bonardi, C., Honey, R. C., \& Hall, G. (1990). Context specificity of conditioning in flavor aversion learning: Extinction and blocking tests. Animal Learning \& Behavior, 18, 229-237.

Bossert, J. M., Liu, S. Y., Lu, L., \& Shaham, Y. (2004). A role of ventral tegmental area glutamate in contextual cue-induced relapse to heroin seeking. Journal of Neuroscience, 24, 10726-10730. 
Bouton, M. E. (1993). Context, time, and memory retrieval in the interference paradigms of pavlovian learning. Psychological Bulletin, 114, 80-99.

Bouton, M. E. (1994). Conditioning, remembering, and forgetting. Journal of experimental Psychology: Animal Behavior Processes, 20, 219-231.

Bouton, M. E. (2011). Learning and the persistence of appetite: Extinction and the motivation to eat and overeat. Physiology \& Behavior, 103, 51-58.

Bouton, M. E. (2014). Why behavior change is difficult to sustain. Preventive Medicine, $68,29-36$

Bouton, M. E., \& Bolles, R. C. (1979). Contextual control of the extinction of conditioned fear. Learning and Motivation. 10, 445-466.

Bouton, M. E., \& Nelson, J. B. (1994). Context-specificity of target versus feature inhibition in a feature negative discrimination. Journal of Experimental Psychology: Animal Behavior Processes, 20, 51-65.

Bouton, M. E., \& Peck, C. A. (1989). Context effects on conditioning, extinction, and reinstatement in an appetitive conditioning preparation. Animal Learning and Behavior, 17, 188-198.

Bouton, M. E., \& Ricker, S. T. (1994). Renewal of extinguished responding in a second context. Animal Learning and Behavior, 22, 317-324.

Bouton, M. E., Todd, T. P., Vurbic, D. \& Winterbauer, N. (2011). Renewal after the extinction of free operant behavior. Learning and Behavior, 39, 57-67.

Bouton, M. E., Winterbauer, N. E., \& Todd, P. T. (2012). Relapse processes after the extinction of instrumental learning: Renewal, resurgence, and reacquisition. Behavioural Processes, 90, 130-141.

Bouton, M. E., \& Woods, A. M. (2008). Extinction: Behavioral mechanisms and their implications. In J. H. Byrne, D. Sweatt, R. Menzel, H. Eichenbaum, \& H. Roediger (Eds.), Learning and memory: A comprehensive reference: Vol. 1, Learning Theory and Behaviour (pp. 151-171). Oxford, UK: Elsevier.

Bouton, M. E., Woods, A. M., Moody, E. W., Sunsay, C., \& García-Gutiérrez, A. (2006). Counteracting the context-dependence of extinction: Relapse and some tests of possible methods of relapse prevention. In Craske, M. G., Hermans, D., Vansteenwegen, D. (Eds.) Clinical application of learning theory. East Sussex, UK: Psychology Press.

Callejas-Aguilera, J. E., \& Rosas, J. M. (2010). Ambiguity and context processing in human predictive learning. Journal of Experimental Psychology: Animal Behavior Processes, 36, 482-494.

Capaldi, E. J. (1994). The sequential view: from rapidly fading stimulus traces to the organization of memory and the abstract concept of number. Psychonomic Bulletin and Review, 1, 156-181. 
Carranza-Jasso, R., Urcelay, G. P., Nieto, J., \& Sánchez-Carrasco, L. (2014). Intertrial intervals and contextual conditioning in appetitive pavlovian learning: Effects over the ABA renewal paradigm. Behavioural Processes, 107, 47-60

Conklin, C. A., \& Tiffany, S. T. (2002). Applying extinction research and theory to cueexposure addiction treatments. Addiction, 97, 155-167.

Crombrag, H.S., Bossert, J.M., Koya, E. \& Shaham, Y. (2008). Context-induced relapse to drug seeking; a review. Philosophical Transactions of Royal Society B, 363, 3233-3243.

Crombag, H. S., \& Shaham, Y. (2002). Renewal of drug seeking by contextual cues after prolonged extinction in rats. Behavioral Neuroscience, 116, 169-173.

Delamater, A. R. (1997). Selective reinstatement of stimulus-outcome associations. Animal Learning and Behavior, 25, 400-412.

Delamater, A. R. (2004). Experimental extinction in Pavlovian conditioning: Behavioural and neurosciences perspective. The Quarterly Journal of Experimental Psychology, 57, 97-132.

Delamater, A. R., \& Westbrook, R. F. (2014). Psychological and neural mechanisms of experimental extinction: A selective review. Neurobiology of Learning and Memory, 108, 38-51. http:/

Epstein, R. (1983). Resurgence of previously reinforced behavior during extinction. Behaviour Analysis Letters, 3, 391-397.

Hall, G. (2002). Associative structures in Pavlovian and instrumental conditioning. In H. Pashler \& R. Gallistel (Eds.), Stevens' handbook of experimental psychology (3rd. ed.) Vol. 3: Learning, motivation and emotion. New York: John Wiley and Sons, Inc.

Hall, G. \& Honey, R. C. (1989). Contextual effects in conditioning, latent inhibition, and habituation: Associative and retrieval functions of contextual cues. Journal of Experimental Psychology: Animal Behavior Processes, 15, 232-241.

Konorski, J. (1948). Conditioned reflexes and neuron organization. London: Cambridge University Press.

Laborda, M. A., McConnell, B. L., \& Miller, R.R. (2011). Behavioral techniques to reduce relapse after exposure therapy: Applications of studies of experimental extinction. In T. Schachtman \& S. Reily (Eds.), Applications of conditioning theory. Oxford, ENG: Oxford University Press.

León, S. P., Abad, M. J. F., \& Rosas, J.M. (2010a). Giving contexts informative value makes information context specific. Experimental Psychology. 57, 46-53.

León, S. P., Abad, M. J. F., \& Rosas, J.M. (2010b). The effect of context change on simple acquisition disappears with increased training. Psicológica, 31, 49-63. 
Lucke, S., Lachnit, H., Koenig, S. \& Uengoer, M. (2013). The informational value of contexts affects context-dependent learning. Learning \& Behavior, 41, 285-297.

Lucke S., Lachnit, H., Stüttgen, M. C. \& Uengoer, M. (2014). The impact of context relevance during extinction learning. Learning \& Behavior, 42, 256-269.

McConnell, B. L., \& Miller, R. R. (2014). Associative accounts of recovery-from-extinction effects. Learning and Motivation, 46, 1-15.

McHugh, L., Procter, J., Herzog, M., Schock, A., \& Reed, P. (2012). The effect of mindfulness on extinction and behavioral resurgence. Learning and Behavior, 40, 405-415.

Miller, H., Lefebvre, O., Lyon, P., Nelson, J. B., \& Molet, M. (2014). A focused attention intervention for preventing the recovery of initial learning. Cognitive Therapy and Research, 38, 6.

Nakajima, S., Tanaka, S., Urushihara, K., \& Imada, H. (2000). Renewal of extinguished lever-press responses upon return to the training context. Learning and Motivation, $31,416-431$.

Nelson, J. B. (2002). Context specificity of excitation and inhibition in ambiguous stimuli. Learning and Motivation, 33, 284-310.

Nelson, J. B. (2009). Contextual control of first- and second-learned excitation and inhibition in equally ambiguous stimuli. Learning \& Behavior, 37, 85-94.

Nelson, J. B. (2013). Mechanism of extinction in emotional regulation. In Hermans, D., Rime, B., \& Mesquita, B. (Eds.) Changing Emotions (pp. 60-65). New York: Psychology Press. Nelson, J. B., \& Bouton, M. E. (1997). The effects of a context switch following serial and simultaneous feature-negative discriminations. Learning and Motivation, 28, 56-84.

Nelson, J. B., \& Callejas-Aguilera, J. E. (2007). The role of interference produced by conflicting associations in contextual control. Journal of Experimental Psychology: Animal Behavior Processes, 33, 314-326.

Nelson, J. B., Lamoureux, J. A., \& Leon, S. (2013). Extinction arouses attention to the context in a behavioral suppression task with humans. Journal of Experimental Psycholgy: Animal Behavior Processes, 39, 99-105.

Nelson, J. B., Lombas, S. \& León, S.P. (2011). Acquisition of appetitive conditioning is not context specific when learned during extinction. Learning \& Behavior, 40, 15-22.

Nelson, J. B., Sanjuan, M. C., Vadillo-Ruiz, S., Perez, J., \& Leon, S. P. (2011) Experimental renewal in humans. Journal of Experimental Psychology: Animal Behavior Processes, 37, 58-70.

Nieto, J., \& Bernal-Gamboa, R. (2013). Recuerdos y olvidos determinados por el entorno. En J. J. Irigoyen, F. Cabrera, M. Y. Jiménez, H. Martínez y K. F. Acuña (Eds.) Estudios sobre comportamiento y aplicaciones Vol. III. (pp.119-130). Sonora, México: Universidad de Sonora. 
Pavlov, I. P. (1927). Conditioned reflexes. London: Oxford University Press.

Pearce, J. M., y Hall, G. (1980). A model for Pavlovian conditioning: Variations in the effectiveness of conditioned but not unconditioned stimuli. Psychological Review, 87, 332-352.

Podlesnik, C. A., \& Kelley, M. E. (2014). Resurgence: Response competition, stimulus control, and reinforcer control. Journal of the Experimental Analysis of Behavior, 102, 231-240.

Podlesnik, C.A., \& Kelley, M. E. (2015). Translational research on the relapse of operant behavior. Mexican Journal of Behavior Analysis, 41, 226-251.

Preston, G. C., Dickinson, A. \& Mackintosh, N. J. (1986). Contextual conditional discriminations. Quarterly Journal of Experimental Psychology: Comparative and Physiological Psychology, 38B, 217-237.

Rescorla, R. A. (2001). Experimental extinction. In R. R. Mowrer \& S. Klein (Eds.), Handbook of contemporary learning theories (pp. 119-154). Hillsdale, N.J.: Erlbaum.

Rescorla, R. A. (2004). Spontaneous recovery. Learning and Memory, 11, 501-509.

Rescorla, R. A. (2008). Within-subject renewal in sign tracking. The Quarterly Journal of Experimental Psychology, 61, 1793-1802.

Rosas, J. M., \& Callejas-Aguilera, J. E. (2006). Context Switch Effects on Acquisition and Extinction in Human Predictive Learning. Journal of Experimental Psychology: Learning, Memory, and Cognition, 32, 461-474.

Rosas, J. M., \& Callejas-Aguilera, J. E. (2007). Acquisition of a conditioned taste aversion becomes context dependent when it is learned after extinction. Quarterly Journal of Experimental Psychology, 60, 9-15.

Rosas, J. M., Callejas-Aguilera, J. E., Ramos-Álvarez, M. M., \& Abad, M. J. F. (2006). Revision of retrieval theory of forgetting: what does make information contextspecific? International Journal of Psychology and Psychological Therapy, 6, 147-166.

Rosas, J. M., García-Gutiérrez, A., \& Callejas-Aguilera, J. E. (2006). Effects of context change upon retrieval of first and second-learned information in human predictive learning. Psicológica, 27, 35-56.

Sánchez-Carrasco, L., González-Martin, G., \& Nieto, J. (2011). Efecto de la duración de la extinción en la reinstauración selectiva de respuestas instrumentales en función de diferentes consecuencias. Psicologica, 32, 323- 345.

Sánchez-Carrasco, L., \& Nieto, J. (2005). Resurgence of three responses sequence in rats. Mexican Journal of Behavior Analysis, 31, 215-226.

Shahan, T. A., \& Sweeney, M. M. (2011). A model of resurgence based on behavioral momentum theory, Journal of the Experimental, Analysis of Behavior, 95, 91-108. 
Tamai, N. \& Nakajima, S. (2000). Renewal of formerly conditioned fear in rats after extensive extinction training. International Journal of Comparative Psychology, 13, 137-147.

Thomas, B. L., Larsen, N., \& Ayres, J. B. (2003). Role of context similarity in ABA, ABC and $A A B$ renewal paradigms: implications for theories of renewal and for treating human phobias. Learning and Motivation, 34, 410-436.

Vila, N. J., \& Rosas, J. M. (2001). Renewal and spontaneous recovery after extinction in a causal learning task. Mexican Journal of Behavior Analysis, 27, 79-96.

Woods, A. M., \& Bouton, M. E. (2007). Occasional reinforced responses during extinction can slow the rate of reacquisition of an operant response. Learning and Motivation, 38, 56-74. 